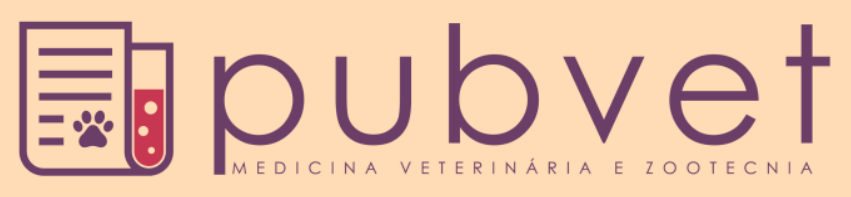

https://doi.org/10.22256/pubvet.v12n4a78.1-7

\title{
Mercado de produtos e serviços para animais silvestres de estimação no município de Belém (PA)
}

\author{
Bianca Barreto Barbosa ${ }^{\circ}$ 1* $^{*}$ Fabrício Khoury Rebello ${ }^{2}$, Marcos Antônio Souza dos \\ Santos ${ }^{\bullet}$, Maria Lúcia Bahia Lopes ${ }^{\bullet} 4$
}

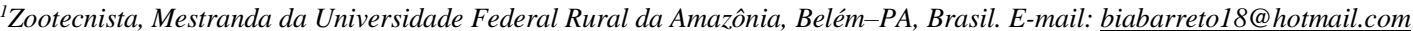
${ }^{2}$ Economista, Prof. Dr. da Universidade Federal Rural da Amazônia, Belém-PA, Brasil. E-mail: fabriciorebello@ hotmail.com ${ }^{3} E_{n g}{ }^{\circ}$ Agr. Prof. Dr. da Universidade Federal Rural da Amazônia, Belém-PA, Brasil. E-mail:marcos.santos@ufra.edu.br

${ }^{4}$ Economista, Prof. ${ }^{a}$ Dra. da Universidade da Amazônia, Belém-PA, Brasil. E-mail: marialucia.lopes@bancoamazonia.com.br *Autor para correspondência

RESUMO. O mercado de animais silvestres para companhia está em constante ascensão. A busca por espécies silvestres tem atraído muitos consumidores e com este crescimento alavanca, também, outros setores como os de produtos, equipamentos e serviços específicos para estes animais. O presente estudo avalia os aspectos da oferta no mercado de Belém (PA), englobando a caracterização dos ofertantes e dos produtos e serviços disponíveis para animais silvestres. O estudo ocorreu em duas etapas. Na primeira, foi realizado um levantamento na Junta Comercial do Estado do Pará (JUCEPA) para identificação de criatórios, pet shops e demais estabelecimentos que comercializam animais, rações, acessórios e que disponibilizam serviços a esse segmento. A segunda etapa consistiu na aplicação de questionários junto aos proprietários dos estabelecimentos identificados na JUCEPA. Utilizou-se a estatística descritiva para avaliação dos resultados. Foram visitados 55 estabelecimentos, abrangendo 18 bairros do município. Do total de estabelecimentos visitados, 20 foram submetidos aos questionários, pois comercializavam produtos ou serviços para animais silvestres. Dos estabelecimentos entrevistados, $70 \%$ são pet shops, $15 \%$ clínicas veterinárias, $10 \%$ lojas de produtos veterinários e 5\% associações de clínicas e pet shops. Os serviços ofertados para animais silvestres e exóticos, nesses estabelecimentos, em ordem decrescente de ocorrência são: atendimento clínico $(26,09 \%)$, exames $(21,74 \%)$, orientação nutricional $(17,39 \%)$, vacinas $(13,04 \%)$, corte de penas e unhas $(13,04 \%)$, orientação de manejo $(4,35 \%)$ e sexaje por DNA para aves $(4,35 \%)$. Apesar da potencialidade desse segmento, ainda se nota uma indefinição de seus contornos, o que também provoca baixo dinamismo nesse mercado. Fatores como a insegurança institucional provocada pela vinculação de informações distorcidas a respeito desse mercado e o desconhecimento do perfil do consumidor por parte dos ofertantes são alguns dos motivos do pouco dinamismo. Algumas alternativas para minimizar esses problemas seriam o aumento da divulgação sobre esse mercado e a oferta de serviços e produtos aderentes às exigências dos consumidores, assim como, a desmistificação quanto a ilegalidade da atividade, a partir da veiculação de informações mais precisas sobre o mercado legal relacionado à fauna silvestre.

Palavras chave: fauna silvestre, mercado, Animais de companhia, pet shop

\section{Product and market service evaluation for wild animals raised as pet in Belém, Pará, Brazil}

ABSTRACT. The market of wild animals for the company is constantly growing. The search for wild species has attracted many consumers and this growth helps other sectors 
such as products, equipment and services specific to these animals. This study evaluates aspects of the existing supply in this market, encompassing the characterization of bidders, products and services available for wild animals in Belém. The study comprising two stages. At first, a survey was conducted in Junta Comercial do Estado do Pará (JUCEPA) for identification of breeders, pet shops and other establishments that sell animals, feed, accessories and provide services to this segment. The second step was the application of questionnaires to the owners of the establishments identified in JUCEPA. The questionnaire was structured in order to know the profile of the bidders and characteristics of the products and services offered. Was used descriptive statistics to evaluate the result. Were visited 55 establishments, including 18 districts of the town. Within the 55 visited places, 20 was submitted to the questionnaires of marketed products or services for wild animals. Considering the people interviewed, $70 \%$ are pet shops, veterinary clinics $15 \%$, $10 \%$ veterinary food stores and 5\% medical associations and pet stores. The services offered to wild and exotic animals in these establishments, in decreasing order of occurrence are: clinical care (26.09\%), examinations (21.74\%), nutritional guidance (17.39\%), vaccines (13.04\%), cutting feathers and nails (13.04\%), management orientation (4.35\%) and sex determination by DNA for birds (4.35\%). Despite the potential, this segment still notice a lack of definition of its contours, which also cause low dynamism in this market. Factors such as the offers not know institutional insecurity caused by binding of distorted information about this market and the consumer profile are some of the causes for the decrease in dynamism. Some alternatives to minimize these problems would be the increased disclosure and the appearance of services and products that meet the demands of consumers and the demystification by linking more precise information on the legal market related to wildlife.

Keywords: wildlife, market, pets, pet shop

\section{Mercado de productos y servicios para animales silvestres de estimación en el municipio de Belém (PA)}

RESUMEN. El mercado de animales silvestres para la compañía está en constante ascenso. La búsqueda de especies silvestres ha atraído a muchos consumidores y éste crecimiento apunta también a otros sectores como los de productos, equipos y servicios específicos para estos animales. El presente estudio evalúa los aspectos de oferta en el mercado de Belém (PA), englobando la caracterización de los ofertantes y de los productos y servicios disponibles para animales silvestres. El estudio se realizó en dos etapas. En la primera, se realizó un levantamiento en la Junta Comercial del Estado de Pará (JUCEPA) para identificación de las tiendas de mascotas y demás establecimientos que comercializan animales, raciones, accesorios y que ponen a disposición servicios a ese segmento. La segunda etapa consistió en la aplicación de cuestionarios junto a los propietarios de los establecimientos identificados en la JUCEPA. Se utilizó la estadística descriptiva para la evaluación de los resultados. Se visitaron 55 establecimientos, abarcando 18 barrios del municipio. Del total de establecimientos visitados, 20 fueron sometidos a los cuestionarios pues comercializaban productos o servicios para animales silvestres. De los establecimientos entrevistados, el $70 \%$ son tiendas de mascotas, $15 \%$ clínicas veterinarias, $10 \%$ tiendas de productos veterinarios y $5 \%$ asociaciones de clínicas y tiendas de mascotas. Los servicios ofrecidos para animales silvestres y exóticos, en esos establecimientos, en orden decreciente de ocurrencia son: atención clínica (26,09\%), exámenes $(21,74 \%)$, orientación nutricional $(17,39 \%)$, vacunas $(13,04 \%)$, corte de plumas y uñas $(13,04 \%)$, orientación de manejo $(4,35 \%)$ y sexo por ADN para aves $(4,35 \%)$. A pesar de la potencialidad de ese segmento, aún se nota una indefinición de sus contornos, lo que también provoca bajo dinamismo en ese mercado. Factores como la inseguridad institucional provocada por la vinculación de informaciones distorsionadas respecto de ese mercado y el desconocimiento del perfil del consumidor por parte de los oferentes son algunos de los motivos del poco dinamismo. Algunas alternativas para minimizar estos 
problemas serían el aumento de la divulgación sobre ese mercado y la oferta de servicios y productos adherentes a las exigencias de los consumidores, así como la desmitificación en cuanto a la ilegalidad de la actividad, a partir de la transmisión de informaciones más precisas sobre el mercado legal relacionado con la fauna silvestre.

Palabras clave: fauna silvestre, mercado, animales de compañía, pets, tienda de mascotas

\section{Introdução}

O gosto popular por animal silvestre mantido em ambiente doméstico não é contemporâneo. Há muito tempo cultiva-se o hábito de possui-lo na condição de ente de estimação, exercendo a função de companhia ao mantenedor. Tal prática evidenciou-se no Brasil, onde a diversidade e a quantidade de animais silvestres, ao longo dos séculos, ensejou um nível de exploração e aproveitamento maior do que o verificado em outros países (Nassaro, 2013)

As espécies silvestres e exóticas perfazem um total estimado de $26,4 \%$ dos animais pets no Brasil. Há mais de 25 mil lojas especializadas na comercialização desses animais e produtos em todo o país (ABRASE, 2012).

Em termos econômicos, o mercado pet brasileiro ocupa o terceiro lugar no ranking mundial, atrás apenas dos Estados Unidos e do Reino Unido, primeiro e segundo lugar respectivamente. De acordo com dados da Associação Brasileira da Indústria de Produtos para Animais de Estimação (ABINPET, 2016), no Brasil, em 2014, o setor faturou cerca de R $\$ 16,7$ bilhões, $9,9 \%$ a mais do que em 2013, quando o faturamento foi de $\mathrm{R} \$ 15,2$ bilhões. O setor pet representa $0,38 \%$ do PIB nacional, e tem aumentado cerca de $11 \%$ ao ano, acumulando $52 \%$ de crescimento nos últimos cinco anos. Este faturamento está associado à comercialização de produtos e serviços denominados pela indústria como Pet serv (serviços), Pet food (alimentação), Pet care (equipamentos, acessórios produtos de higiene e beleza animal) e Pet vet (medicamentos veterinários). $\mathrm{O}$ setor de maior faturamento para animais silvestres, em 2011, foi o de rações e suplementos $(43,5 \%)$, seguido de equipamentos e acessórios $(29,2 \%)$ e de comércio de animais $(26,37 \%)$. Os demais setores como serviços veterinários e similares (biólogos, zootecnistas e laboratoriais) ficaram com menos de $1 \%$ do faturamento (ABRASE, 2012).

O grande potencial de crescimento do setor pet para animais silvestres está diretamente ligado à constante ascensão do mercado pet convencional. Esse crescimento alavanca outros setores como os de produtos, equipamentos e acessórios específicos para espécies silvestres, além do mercado de trabalho especializado constituído por zootecnistas, médicos veterinários, tratadores entre outros profissionais.

O presente estudo apresenta os resultados obtidos a partir do levantamento de dados primários junto a estabelecimentos comerciais com atuação no mercado de animais silvestres. Os resultados mostram o perfil socioeconômico dos entrevistados, caracterização dos estabelecimentos, produtos e serviços ofertados, além das perspectivas para o futuro deste mercado. Trabalhos dessa natureza são importantes para orientar a expansão planejada do segmento, fortalecendo, desta forma, o mercado legal para a oferta de animais silvestres e, da mesma forma, contribuído para reduzir o mercado clandestino que ainda existe.

\section{Material e Métodos}

O estudo foi realizado no município de Belém, capital do estado do Pará, englobando 18 bairros com representatividade no número de estabelecimentos atuando no mercado pet. Os bairros estão localizados em estratos de renda distintos (baixa, média e alta). Belém destaca-se por ser o maior centro populacional do estado do Pará, com número estimado em 1.439.561 habitantes e o $2^{\circ}$ mais populoso da Amazônia (IBGE, 2015), fato que proporciona uma dimensão da relevância em se conhecer os aspectos deste mercado.

O estudo levantou a existência de 107 estabelecimentos com atuação no segmento, sendo 96 identificados a partir da Junta Comercial do Estado do Pará (JUCEPA) e 11 obtidos a partir de diversas mídias de publicidades locais (internet, jornais, lista telefônica). Desses estabelecimentos foi realizada visita em 55 estabelecimentos e aplicado um questionário semiestruturado em 20, pois nos demais foram constadas situações como: não desenvolvia mais, no momento da visita, atividade relacionada ao objeto do estudo $(82,8 \%)$, mudança de ramo de atividade (14,3\%) e mudança de endereço do estabelecimento $(2,9 \%)$. 
Os questionários foram estruturados visando conhecer o perfil dos empreendedores e da oferta, identificando as características do estabelecimento comercial, tipo de serviço prestado ao consumidor, opinião dos entrevistados sobre os aspectos legais da comercialização e suas expectativas para o futuro desse mercado. As visitas de campo foram realizadas no período de junho a novembro de 2015. A partir daí, montouse um banco de dados que foi analisado com base na estatística descritiva.

\section{Resultados e Discussão}

A maioria dos entrevistados eram mulheres (75\%). A faixa etária variou entre 22 e 57 anos, sendo que $45 \%$ tinham entre 31 e 50 anos, seguidos da faixa entre 22 a 30 anos (40\%). O grau de instrução dos entrevistados estava entre o secundário incompleto e o superior completo como se pode observar na Tabela 1. As maiores participações foram nível superior completo (30\%), nível superior incompleto (30\%) e secundário completo $(20 \%)$. Os dados mostram que a maioria dos entrevistados possui grau de escolaridade elevado. Dos entrevistados, 35\% eram os proprietários do estabelecido, $20 \%$ exerciam a função de responsáveis técnicos (Médico Veterinário) e os demais respondiam pela área de atendimento ao cliente.

Tabela 1. Grau de instrução dos entrevistados.

\begin{tabular}{lcc}
\hline Grau de Instrução & Frequência & $\%$ \\
\hline Secundário Completo & 4 & 20 \\
Secundário Incompleto & 3 & 15 \\
Superior Completo & 6 & 30 \\
Superior Incompleto & 6 & 30 \\
Não informou & 1 & 5 \\
\hline Total & 20 & 100 \\
\hline
\end{tabular}

Fonte: dados da pesquisa (2015).

O tempo de funcionamento da maioria dos estabelecimentos (35\%) é de 2 a 5 anos (Tabela 2). Nota-se que $65 \%$ deles são novos entrantes, ou seja, empresas novas no mercado. Através dos relatos dos entrevistados, foi possível notar, em certo grau, o desconhecimento quanto aos aspectos legais referentes ao mercado pet para animais silvestres. Algumas dessas empresas possuem dificuldade na sua inserção e fixação neste mercado, fechando as portas com pouco tempo de funcionamento.

Os estabelecimentos eram pet shops (70\%), clínicas veterinárias (15\%), lojas de produtos veterinários (10\%) e associações de pet shops e clínicas (5\%). Em relação ao quadro de funcionários a prevalência $(60 \%)$ foi de 1 a 3 trabalhadores divididos em funções como atendentes, médicos veterinários e tosadores.

Tabela 2. Tempo de funcionamento dos estabelecimentos, 2015.

\begin{tabular}{lcc}
\hline Tempo de funcionamento & Frequência & $\%$ \\
\hline 1 a 2 anos & 6 & 30 \\
Mais de 2 a 5 anos & 7 & 35 \\
Mais de 5 a 10 anos & 3 & 15 \\
Acima de 10 anos & 3 & 15 \\
Não informou & 1 & 5 \\
\hline Total & 20 & 100 \\
\hline
\end{tabular}

Fonte: dados da pesquisa (2015).

Entre os estabelecimentos visitados não houve registro da comercialização de animais silvestres, no entanto, quatro estabelecimentos vendem animais exóticos. Os animais exóticos comercializados são: hamster chinês (Cricetulus griseus), porquinho-da-índia (Cavia porcellus), calopsitas (Nymphicus hollandicus), periquito australiano (Melopsittacus undulatus) e tigre d'água (Trachemys dorbigni).

A oferta de serviços para animais silvestres e exóticos foram constatados em 35\% dos estabelecimentos. Entre os serviços demandados, em ordem decrescente de ocorrência, estão (Figura 1): atendimento clínico $(26,1 \%)$, exames $(21,7 \%)$, orientação nutricional $(17,4 \%)$, vacinas $(13,0 \%)$, corte de penas e unhas $(13,0 \%)$, orientação de manejo $(4,4 \%)$ e sexagem por DNA para aves $(4,4 \%)$.

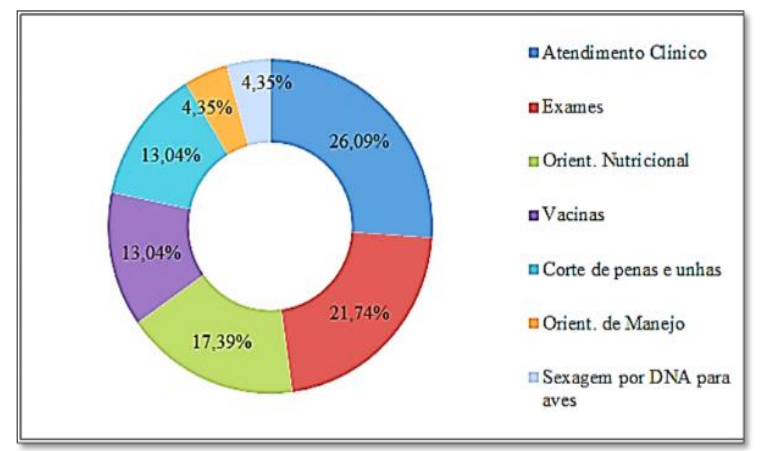

Figura 1. Serviços ofertados aos animais silvestres e exóticos. Fonte: dados da pesquisa (2015).

A reduzida demanda por serviço de sexagem por DNA para aves deve-se ao fato do exame não ser realizado no próprio estado. O material coletado é enviado para análise em estados das regiões Sudeste e Centro-Oeste do País, tornando 
o resultado do exame demorado e oneroso. Por esse motivo, muitos consumidores não requerem este tipo de serviço.

Notou-se também que há uma vinculação entre empresas que comercializam acessórios, medicamentos e outros produtos com as empresas que prestam atendimento clínico e demais serviços aos animais silvestres. Essa é uma prática comercial que visa ampliar a carteira de clientes com a indicação de empresas parceiras e com atitudes reciprocas.

Segundo 65\% dos entrevistados não é possível fazer uma identificação exata do perfil dos seus clientes. Esse fato mostra que é necessário um esforço maior do empreendedor para ampliar o conhecimento sobre as necessidades dos consumidores como forma de ampliar a participação do setor no mercado. Esse resultado coincide com os encontrados por Pereira Junior et al. (2014) no município de São João da Barra (RJ).

Conhecer o perfil dos clientes (demandantes) é uma das principais atitudes que o empreendedor precisa tomar para obter êxito nos negócios, pois fornece a base para que o empreendedor atue de modo a satisfazer as vontades de seu público (Kotler \& Armstrong, 2012). Quando o empreendedor conhece seu cliente consegue atendê-lo melhor o que pode contribuir para a expansão dos negócios.

De qualquer forma, os entrevistados souberam dar algumas pistas quanto às principais justificativas relatadas por seus clientes para a aquisição de animais silvestres e serviços a esse segmento: afeição pelo animal (20\%), criação de animal diferente $(5 \%)$, presentear alguém $(5 \%)$, questão cultural de criar animais silvestres na região Norte $(5 \%)$ e a maioria $(65 \%)$ não soube responder.

O comportamento do consumidor em suas escolhas reflete várias perspectivas, incluindo motivações culturais, sociais, psicológicas, demográficas, econômicas, entre outras. Por outro lado, a fascinação das pessoas pelos animais silvestres em razão do seu caráter exótico, também porque é raro, faz com que sua procura seja grande, inversamente proporcional a quantidade de espécimes legalmente disponíveis (Nassaro, 2013). Por esse motivo é grande o número de pessoas que possuem em seus domicílios animais silvestres que necessitam de cuidados e produtos especiais, ainda que não possuam registro legal.
Sobre a razão da preferência, pode-se aferir que particularmente alguns animais silvestres são muito desejados porque são mais chamativos que os domésticos tradicionais, o que valoriza sua função "decorativa" no ambiente domiciliar, fora as habilidades exclusivas de algumas espécies no que se refere ao canto. Como se não bastassem tantos atrativos, alguns animais, como o papagaio e algumas araras, têm também a capacidade de repetir, com voz semelhante à humana, o que ouvem à sua volta, além de criar com seu proprietário laços afetivos.

Um dos principais custos para a criação de qualquer animal está relacionado a compra de ração. A disponibilidade de rações comerciais de qualidade ainda é um desafio para produtores e comerciantes e apesar disso o setor intitulado "Pet food" relacionado à alimentação, foi o que mais gerou lucro em 2014, com um faturamento avaliado em $67,3 \%$ segundo o levantamento da Associação Brasileira das Indústrias de Produtos para Animais de Estimação (ABINPET, 2016).

É de se esperar que ocorram muitos gastos com a nutrição, sendo item indispensável para a vida de qualquer animal, no entanto, os consumidores estão cada vez mais exigentes por alimentos específicos para as espécies e que atendam seus hábitos alimentares proporcionando elevados níveis nutricionais.

No estudo, em $30 \%$ dos estabelecimentos foi possível encontrar rações para animais silvestres e em 20\% rações para animais exóticos. Apesar do número maior de disponibilidade por estabelecimento de rações para animais silvestres, em termos de diversificação de produtos, as ofertas de rações para animais exóticos ganham destaque, uma vez que disponibiliza diversas marcas de rações para uma variedade maior de animais, como mostra o Quadro 1.

Os preços das rações para animais silvestres variaram de $\mathrm{R} \$ 4,00$ (kg/ração para aves pequenas) a $\mathrm{R} \$ 17,00$ (kg/ração para aves de grande porte). A média dos preços foi de $\mathrm{R} \$ 9,17$, por quilo, para rações de animais silvestres e de $\mathrm{R} \$ 6,92 / \mathrm{kg}$ para rações destinadas aos animais exóticos. Estes produtos são comercializados em embalagens de um quilograma $(1 \mathrm{~kg})$ ou vendidos a granel.

Em relação à comercialização de utensílios e acessórios para animais silvestres, $30 \%$ dos entrevistados relataram disponibilizar em seus 
estabelecimentos itens como bebedouros, comedouros, gaiolas, brinquedos e acessórios.

Quadro 1. Variedade de marcas de rações para animais silvestres e exóticos.

\begin{tabular}{|c|c|c|}
\hline Rações & Marcas & Indicação \\
\hline \multirow{2}{*}{ Animais Silvestres } & Pássaro Forte & Papagaios e araras \\
& Nutriave & Papagaios \\
& Alcon club & Répteis (Jabuti) \\
\hline \multirow{2}{*}{ Animais Exóticos } & Roi & Chinchila \\
& Funy Bunny & Chinchila e cobaia \\
& Pássaro Forte & Calopsita \\
& Sinfonia & Canário \\
& Produtos Águia & Periquito \\
& Nutriave & Agarponis \\
\hline
\end{tabular}

Fonte: dados da pesquisa (2015).

Quando questionados sobre o tipo de órgão fiscalizador que inspeciona os estabelecimentos e a frequência das visitas, os principais nomes citados foram o Conselho Regional de Medicina Veterinária (30\%), representantes da Vigilância Sanitária (25\%) e da Secretaria Municipal de Meio Ambiente (15\%). Os demais (30\%) não souberam responder.

A maioria dos entrevistados (90\%) relatou que as visitas não são periódicas e que acontecem pelo menos uma vez ao ano. Apenas dois entrevistados, que tinham em comum o endereço situado em duas feiras públicas de Belém, disseram que a fiscalização é frequente e costuma surpreender os comerciantes, principalmente dos agentes da Secretaria Municipal do Meio Ambiente (SEMMA), órgão responsável por planejar, coordenar, supervisionar, executar e controlar atividades relacionadas a proteção do meio ambiente.

Em relação às perspectivas, para os próximos cinco anos das atividades de comercialização no segmento pets silvestres, as opiniões divergiram. A visão positiva de $20 \%$ dos entrevistados projeta um mercado em plena expansão, no entanto, outros $20 \%$ discordam e cogitam um mercado estagnado e em crise, com drásticas reduções dos níveis atuais da atividade. Os outros $60 \%$ não souberam responder. Os entrevistados que preferiram não opinar sobre esse assunto, relataram, no entanto, existir muitas incertezas sobre o futuro deste mercado, uma vez que, a legislação referente ao comércio de animais silvestres é muito restritiva. A insegurança institucional desse mercado é, portanto, uma ameaça considerada pelos empresários do setor.

\section{Conclusões}

Os proprietários ou responsáveis administrativos pelos estabelecimentos não possuem bem caracterizado $\mathrm{o}$ perfil dos demandantes dos produtos e serviços que oferecem. Esse reconhecimento é primordial para a condução de uma oferta que atenda as exigências do consumidor e que deslumbre a ampliação dos negócios. Faz-se necessário, portanto, o reconhecimento das necessidades do mercado.

Parte dos proprietários não possuem perspectivas positivas para o futuro do segmento. Essa visão de incerteza é principalmente gerada pela visível insegurança institucional, pois as autoridades responsáveis não criam bases sólidas para a construção de um mercado mais estruturado e consolidado, criando dúvidas sobre sua legalidade. O poder público demorou a liberar a criação de espécies silvestres para a venda. A bem pouco tempo, sequer havia disponibilidade de espécimes silvestres no mercado formal. Esse histórico de carência de atitudes para tornar o comércio legal efetivo, refletiu na atual situação da oferta de produtos e serviços para abastecer este mercado.

A divulgação dos serviços pelos estabelecimentos ainda é tênue se comparada ao marketing realizado para as atividades destinadas aos animais domésticos convencionais. A justificativa levantada no estudo seria a demanda não recorrente por esses serviços. No entanto, os consumidores não podem adquirir um produto ou serviço que eles não conhecem, muito menos se este não atende as necessidades muito peculiares de um pet silvestre. Alguns serviços como a sexagem por DNA para aves podem ser substituídos por outros que já são consolidados no mercado pet convencional e que podem ser realizados rapidamente e a preços reduzidos. Uma proposta seria a oferta de serviços diferenciados como a hospedagem segura para animais silvestres e exóticos, que é disponibilizada tradicionalmente para pets convencionais e até mesmo para animais silvestres como ocorre no município de São Paulo, por exemplo.

Apesar da potencialidade desse segmento, nota-se, ainda, uma indefinição de seus contornos, 
o que também acarreta o reduzido dinamismo do mesmo. Torna-se necessário, portanto, o incentivo por parte do estado, através dos órgãos competentes, para a desmistificação sobre a ilegalidade da atividade, uma vez que existe a possibilidade de oferta de animais a partir de criatórios autorizados. Ações como campanhas de esclarecimento sobre o assunto, realizadas pelos órgãos ambientais, com o intuito de melhorar a interpretação da legislação pertinente se fazem necessárias. Aos empresários cabem as ações de marketing e de inovação dos produtos e serviços ofertados.

Suprir a carência do mercado com animais legalizados, a oferta de produtos e serviços de qualidade, a repressão a práticas ilegais e o esclarecimento de dúvidas sobre a legislação podem ser medidas importantes para a organização do uso dos recursos naturais e para o desenvolvimento regional, onde cabe um papel ao segmento pet para animais silvestres.

\section{Referências Bibliográficas}

ABINPET. 2016. Caderno especial AbinpetAssociação Brasileira da Indústria de Produtos para Animais de Estimação. AgroANALYSIS, 35, 35-40.

ABRASE. 2012. Relatório do Mercado Nacional de Fauna Silvestre e Exótica: segmento Rio de Janeiro e São Paulo. In: ABRASE (ed.) 4 ed., São Paulo, Brasil.
IBGE - Instituto Brasileiro de Geografia e Estatística. 2015. Classificação Nacional de Atividades Econômicas - CNAE Web. Disponível em: < http://www. cnae.ibge.gov.br/> (Acesso em: 2811 2018).

Kotler, P. \& Armstrong, G. 2012. Princípios de marketing, Brasil.

Nassaro, A. L. F. 2013. Animais silvestres e o propósito da estimação. MPG Jurídico, 1, 4047.

Pereira Junior, G., Souza, F. S. \& Sousa Barbosa, P. 2014. Perfil mercadológico do segmento de produtos veterinários para cães e gatos na Cidade de São João da Barra-RJ. PUBVET, 8, 230-339.

\section{Article History: \\ Received 29 November 2017 \\ Accepted 19 January 2018 \\ Available online 9 April 2018}

License information: This is an open-access article distributed under the terms of the Creative Commons Attribution License 4.0, which permits unrestricted use, distribution, and reproduction in any medium, provided the original work is properly cited. 